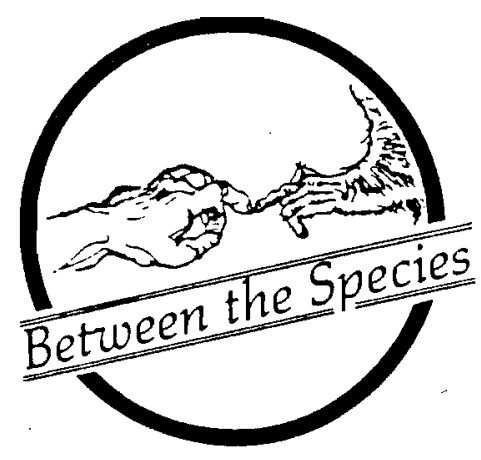

\title{
CANNIBALISM, VEGETARIANISM, AND NARCISSISM
}

Richard Huber. Treasur

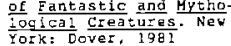

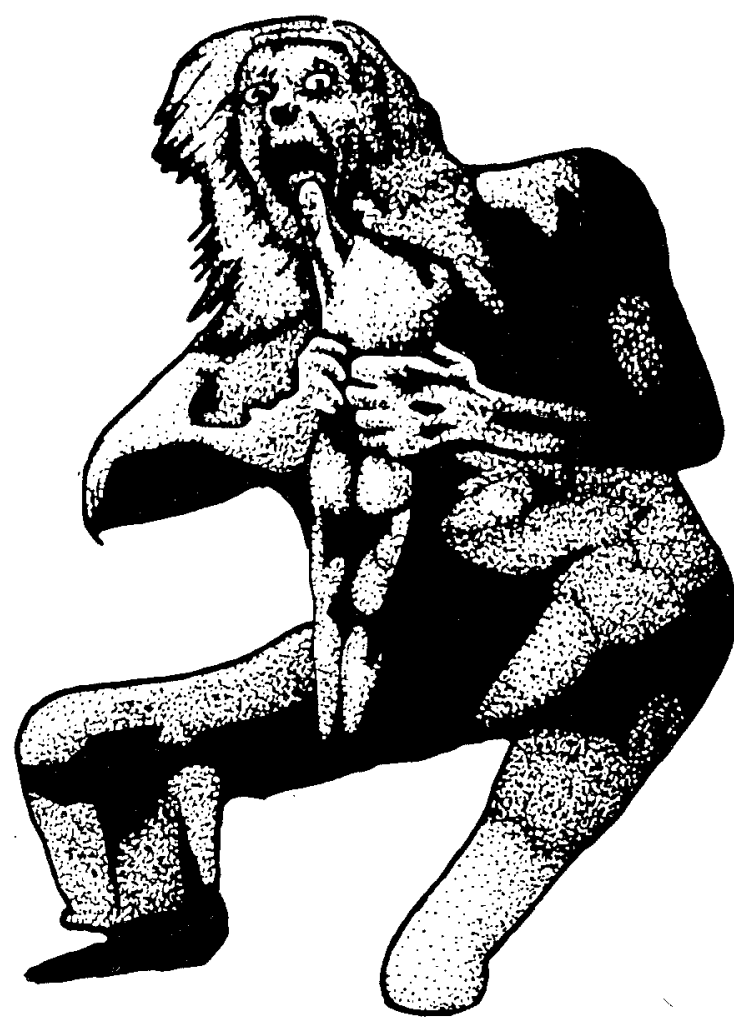

William B. Irvine

Wright State University

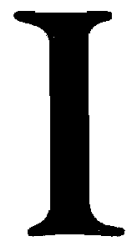

$\mathrm{n}$ this paper I will focus on two questions that people in general, and philosophers in particular, generally refuse to take seriously: Why is it morally wrong to kill people for trivial reasons (e.g., to barbecue them), and why is it morally permissible to kill animals (i.e., nonhuman animals) for trivial reasons? I will not attempt to answer these questions; rather, my interest is in why it is that so many people refuse to take them seriously. I will argue that when it comes to developing an "ethics of eating," the stomach all too often triumphs over the mind.

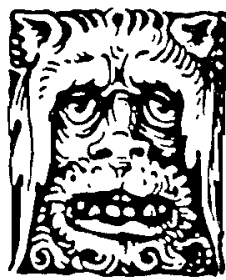

PHILOSOPHY 


\section{Two Modest Proposals}

When I teach introductory ethics, I like to befuddle my students by proposing a business venture. I tell them that I have learned of the existence of the Millionaire Gourmets' Club, which is willing to spend vast sums of money to obtain nice fat babies to roast. I suggest that we try to profit from my discovery by starting a baby-ranching business. What we would do is find women who, for money, are willing to become impregnated by paid sperm donors. Both the women and the sperm donors would be fully informed about our plans. Any babies produced would be placed on our baby ranch; there we would fatten them, slaughter them ("slaughter" is such an ugly word; perhaps we should instead say that we would "harvest" them), and then sell the carcasses (whoops, another ugly word) to the Millionaire Gourmets' Club.

My students, needless to say, are shocked by my proposal. They tell me that my babyranching venture would be nothing more than an institutionalized form of murder. They tell me that they would have no part in such a venture - and they often add that the whole idea is, to use their terminology, "gross and disgusting."

What my students are objecting to is the active cannibalism that my baby-ranching plan would involve - active because the people eaten are killed so that they can be eaten. As it so happens, my students are also opposed to passive cannibalism, which involves, for example, eating people who died natural deaths.

My students' aversion to passive cannibalism becomes apparent when I propose a second business venture to them. I point out that in many countries people are starving to death and that in even more countries people have insufficient protein in their diets. I suggest that we remedy this situation - and make a profit at the same time - by acquiring the bodies of people who died natural deaths and selling the meat abroad. (We might gain a "property right" to someone's body by paying him today for the use of his body when he dies.) I point out that it is shamefully wasteful to dispose of corpses the way we now do - namely, by contaminating them with embalming fluid and then burying them in the ground.

My students, on hearing this proposal, sometimes object that the meat of a dead person would be unsafe to eat, inasmuch as it might be contaminated with germs, the very germs that killed the person in question. In reply to this claim, I have three things to say. First, I point out that we could be selective about which corpses we sold; we could, for example, specialize in the relatively germ-free bodies of people who had died of heart attacks. Second, even if a corpse had some germs, most of these would be killed by cooking the corpse. Third, even if we sold corpses that could not be disinfected by cooking, we still might be justified in selling them: for the starving people in many parts of the world, tainted meat is better than no food at all.

Another common objection against passive cannibalism is that practicing it will, in the long run, tend to reduce our respect for our fellow humans and will thereby make it more likely that we will violate the rights of our fellows. ${ }^{1}$ In reply to this objection I point out that there are documented cases in which people have practiced passive cannibalism for generations and have nevertheless maintained their respect for their fellow humans. ${ }^{2}$ And even if it were possible that the practice of passive cannibalism would lessen our respect for our fellow, isn't this potential evil 
outweighed by the actual evil that results from our burying perfectly good meat and thereby condemning distant peoples to death by starvation?

My students are not alone in their aversion to cannibalism. In our culture people in general feel a strong enough aversion to have made cannibalism a serious crime. In Ohio (where I now reside) the law does not mention cannibalism as such. One can nevertheless draw the conclusion that active cannibalism is illegal inasmuch as it involves murder, and one suspects that passive cannibalism is also illegal, inasmuch as it involves abuse of a corpse. According to Ohio law, it is a fourth-degree felony to "treat a human corpse in a way that would outrage reasonable community sensibilities." 3 Judging from my students' reaction, people in my community do not look fondly on acts of passive cannibalism.

When we turn our attention to other cultures, even "primitive" ones, we find that they, too, are generally opposed to cannibalism in either of its forms. And even before the spread of Christianity the practice of cannibalism was rare. ${ }^{4}$ As taboos go, the cannibalism taboo would seem to put the incest taboo to shame.

To be sure, the law and people in general distinguish between what might be termed recreational and non-recreational cannibalism. There is, many would claim, an important moral difference between eating a dead person simply to have a novel culinary experience and eating a dead person to avoid starvation. Various members of the Donner party, for example, resorted to non-recreational passive cannibalism when confronted with starvation; they were subsequently forgiven at least in the eyes of the law. It was only when active cannibalism was suspected that legal action was even threatened. 5
It is interesting to note, though, that even though the public in some sense forgives acts of non-recreational passive cannibalism, it simultaneously finds these acts horrible. So strong is our aversion to cannibalism - even to non-recreational passive cannibalism that there have been many people who have chosen to die rather than eat human flesh, and many of those who have avoided death by resorting to passive cannibalism have typically suffered greatly before doing so. They preferred to eat a shoe - or at least try to than eat human flesh.

Although people are generally opposed to eating people, they rarely (in our culture, at any rate) share the same qualms about eating animals. To be sure, people have pronounced likes and dislikes concerning animal flesh.

Although beef, pork, and chicken are popular with Americans, relatively few of them will eat frogs, rabbits, dogs, cats, or horses. Nevertheless, they tend not to make a moral issue out of their dislikes. As far as I can tell, in much of America you can eat anything you want as long as it isn't a fellow human being. There are laws against cruelty to animals, but the law says surprisingly little about the uses to which dead animals can be put.

By way of illustration, in Ohio there are laws dealing with the consumption of "higher animals" (e.g., dogs and horses) by people; these laws, however, are intended not so much to prevent these higher animals from being consumed as to prevent people from unwittingly being sold or served the flesh of a higher animal when they think they are eating, say, beef. Thus, the state of Ohio requires any establishment serving horse meat to post in a conspicuous place a sign, "which shall be white and not less than twelve by eighteen inches in size, upon which shall be printed in plain black Roman letters, ... 
'Horse Meat Served Here' " 6 In Ohio it isn't a crime to sell horse meat or to eat it; the crime is in passing off horse meat as some other kind of animal flesh.

\section{Cows and People}

It is fairly clear, then, that in America and in much of the world a human corpse is more of a sacred thing than is a living cow: to defile a corpse - which of course is incapable of suffering - is a far greater crime than is causing a cow significant discomfort and suffering simply so that one can enjoy a Big Mac. 7

This raises an important question: is there really that much difference between people and cows that you can kill and eat cows and (most Americans would claim) raise no important moral issues, but that you can't eat people (even ones who have died natural deaths) without committing acts of moral depravity?

We have now reached the heart of the issue: are there important (i.e., morally significant) differences between cows and people? And if so, what are they? Unless we are able to point out such differences, then it would seem that we are inconsistent when we hold - as people typically do - that it is morally permissible to eat cows but not people. If we wish to be consistent, we would have to hold either (i) that both eating cows and eating people are morally permissible or (ii) that neither eating cows nor eating people is morally permissible. If we choose the second alternative, we end up - if we are moral people, at any rate - as vegetarians, and if we choose the first alternative, we must drop our objections to cannibalism, passive or otherwise.

My students feel confident that they can explain (even to someone as apparently dense as their instructor) the difference between cows and people - i.e., the difference that allows us to say that cattle ranching is morally permissible but that baby ranching is not. Here are some of the explanations they typically offer, together with the reason why these explanations are unacceptable.

(1) Cows don't mind being killed - or at any rate, they don't protest when we kill them. This answer won't do, though, since the babies involved in my baby-ranching scheme are unlikely to protest when we kill them. Consequently, this "difference" isn't a difference at all.

(2) We kill cows in a painless way. One wonders whether this is true, but even it if were, it won't do as an answer. Notice after all, that the babies in my baby-ranching scheme will be killed in a painless way. So again, the alleged difference is not really a difference.

\section{T $t$ is fairly clear, then, that 1 in America and in much of the world a human corpse is more of a sacred thing than is a} living cow: to defile a corpse is a far greater crime than is causing a cow significant discomfort and suffering simply so that one can enjoy a Big Mac.

(3) We raise the cows just so we can eat them, and since we bring the cows into existence, we have the right to end their lives as we see fit. Again, this answer won't do since in my baby. 
ranching scheme we are bringing the babies into existence that we eventually "harvest." We "made" these babies; few would go on to infer, however, that this gives us the right to kill and eat them.

(4) People have souls; cows don't. The basic problem with this response is that souls are not observable, so the claim made does not appear to be one that we can test empirically. And although one can accept the above claim as a "leap of faith," it is a leap that many people are unwilling to take.

(5) People have a right to life; cows don't. This is a terrific response but for one thing: it begs the question. What I am asking, after all, is this: what difference is there between people and cows that gives people but not cows a right to life? The answer to my questions cannot be that people have a right to life but cows don't.

(6) People are capable of rational thought; cows are not. This answer, by the way, is the one that many philosophers (including, I think, Kant) will give.

I agree that people do have a greater capacity for rational thought than cows. (What I mean to say, of course, is that most people have a greater capacity for rational thought than most cows.) The problem is that I don't agree that this difference is an important difference - or at least not one important enough to account for the disparity between our views on the moral acceptability of eating people and our views on the moral acceptability of eating cows.

Why is capacity for rational thought such an important thing? One answer that is commonly given to this question is that capacity for rational thought is valuable and important because it lets us do valuable and important things. What things? Well, things animals can't do, like manufacture automo- biles, build bridges, paint pictures, program computers, and write philosophy papers.

The problem with this line of response is that it just pushes our inquiry back one step. Now we must ask why the abilities just described are so important - and in what sense they are important.

If it be answered, as it often will, that these abilities are important because they enable us to advance our interests (life is easier if you can drive across a bridge instead of having to swim across a river), the narcissism of our value system becomes apparent: to say an action is good is to say it is good for people. ${ }^{8}$ It also becomes apparent how convenient this line of response is for us as a species.

A cynic might, at this point, suggest that what we have done in selecting the capacity for rational thought as the thing that distinguishes us from the other animals is to demonstrate our superiority over the other animals by choosing an ability that we have and they lack and by saying that this ability is the one that matters. Why are we so great? Because we are like we are. Why are the other animals morally insignificant? Because they are unlike us.

There are, to be sure, other ways to answer the questions, "Why is rational thought so important?" I will not take time to describe these answers; I will, however, point out that any such answer must not only presuppose a value system but presumably a value system that is "biased" in favor of the interests of human beings. Before one can point to a difference between cows and people as being ethically significant, one must already have ethical values. For this reason, our attempt to point out the ethically significant difference between people and cows raises more questions than it answers. 
I, for one, suspect that the differences between people and cows are not that great - and certainly not great enough to justify the disparity between our moral views concerning people and our moral views concerning cows. Unless we assume that people are terrific and cows aren't, I doubt that we will ever be able to prove as much.

\section{Concluding Remarks}

Some might, at this point, wonder whether the above remarks constitute an ethical argument for vegetarianism - or at least show that the ethical beliefs of the vegetarian are more consistent than those of the non-vegetarian. I wish they did, but I fear they do not.

Notice, once again, that from the view that there are no important differences between people and cows, it does not follow that vegetarianism is morally obligatory. What does follow, as was mentioned above, is one of two things: either vegetarianism is morally obligatory, or cannibalism is morally permissible. It will take further argument to establish one of these disjuncts as the correct view.

Another thing to realize is that in the same way as a non-vegetarian might be guilty of inconsistency when she refuses to engage in cannibalism (passive or otherwise), a vegetarian might also be guilty of inconsistency when she refuses to eat the meat of an animal who lived a "natural life" and died a "natural death."

Suppose, then, that some animal has lived a natural life and died a natural death. As a result we find ourselves with a body to dispose of. We can eat it, or we can feed it to carnivorous animals, or we can bury it. What I want to suggest is that in a world with starving people - and starving animals, for that matter - it makes little sense to waste this food by burying it. If we value the lives of people and animals, shouldn't we in these cases advocate the consumption of animal flesh?

Indeed, I know of one author who argues that we are guilty of waste when we bury the millions of dogs and cats we annually destroy. ${ }^{9}$ This author would, of course, prefer that we not destroy these animals, but once we have destroyed them, does it make sense to dispose of their meat as if it were so much garbage?

In short, the hard-core vegetarian who declares that it is never morally permissible to consume animal flesh might be guilty of inconsistency. Of course, few vegetarians are "hard core" in the sense intended.

If what I have said in this paper is correct, many people have an inconsistent "ethics of eating." Why the inconsistency? Because, I think, they have allowed their stomachs to triumph over their minds. Our food prejudices are so strong that we will typically reject any ethical system that disagrees with them - even though doing so means falling into inconsistency.

Although they would typically be reluctant to admit it, many grown-up philosophers have a hard time reasoning their way around their upbringing. Someone raised on Big Macs might, on obtaining his philosophy Ph.D., find it easy to prove that cows lack a right to life. At the same time, though, one can imagine that if his culture had been different - if, for example, this philosopher had been raised to think of cows as sacred he would, as an adult, be able to invent any number of arguments to show that both cows and people have rights. Similarly, if human physiology required us to engage periodically in cannibalistic acts to remain healthy, our ethicists would probably come up with persuasive arguments in favor of cannibalism.

Am I suggesting, then, that much of moral 
philosophy is little more than an attempt to "rationalize" our moral intuitions? Indeed I am. I strongly suspect that our ethical "gut feelings" - about murder, about cannibalism, about the value of human life in general are the "data" against which we test ethical theories. When an ethical theory doesn't properly "account for" our favored set of ethical data (i.e., our ethical "gut feelings"), we reject the theory. It can also happen that we discard ethical data in light of an ethical theory, but this is much less common.

I suspect that some of my readers have found this a disgusting paper, a paper not to read before mealtime. I apologize for this, but at the same time I urge my readers to examine their feelings of disgust and to ask whether these feelings have had any significant influence on their ethical views. And to those of you who have been led to vegetarianism by ethical arguments, let me offer a piece of advice: your real job is not so much to persuade the minds of carnivores as to persuade their stomachs. Where their stomachs go, their minds will surely follow.

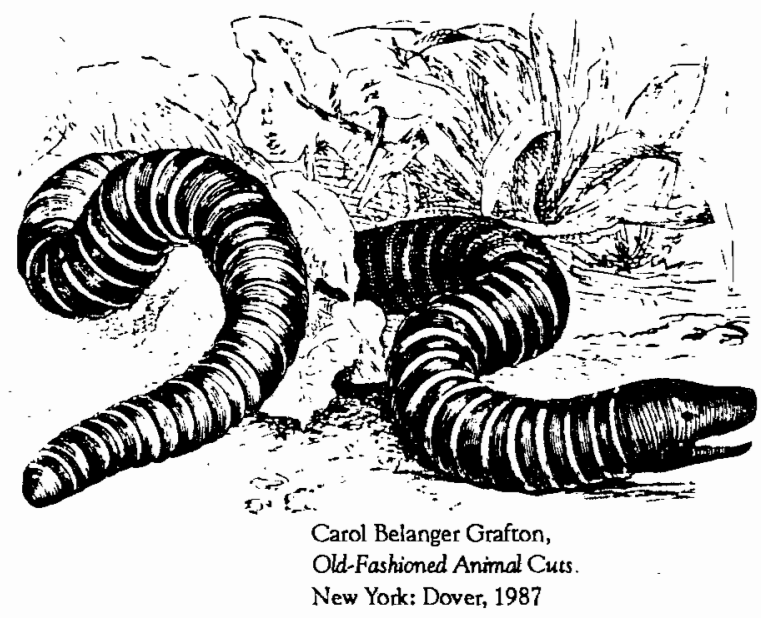

\section{$\underline{\text { Notes }}$}

${ }^{1}$ Kant and Aquinas, for example, take this line. For more on this point see Tom Regan's "Ethical Vegetarianism and Commercial Animal Farming," Today's Moral Problems, 3rd ed., Richard A. Wasserstrom, ed., (New York: Macmillan Publishing Company, 1985), pp. 461-2.

2 See, for example, Peggy Reeves Sanday's accounts of the passive cannibalism in Divine Hunger: Cannibalism as a Cultural System (Cambridge: Cambridge University Press, 1986). Of particular interest is her account of the passive cannibalism of the Gimi women of New Guinea.

3 Ohio Revised Code, sec. 2927.01. It is, by the way, interesting to note how the use of a "community standards" yardstick in this law parallels that in obscenity laws.

${ }^{4}$ Indeed, one anthropologist has gone so far as to claim that cannibalism has never existed. See Sanday's discussion of this issue on pp. 8-10 of Divine Hunger.

5 See George R. Steward's Ordeal by Hunger: The Story of the Donner Party, new ed., rev. and enl., (Boston: Houghton Mifflin Company, 1960), pp. 287-93.

6 Ohio Revised Code, sec. 919.07.

7 A related claim can be made about medical experimentation. Recently there was a public outcry concerning medical experimentation on brain-dead human beings. (See, for example, Richand Koenig's "Doctors Use Brain-Dead Patient to Test Centocor Inc.'s New AntiClotting Drug," Wall Street Joumal, 17 October 1988, p. B3.) Many of those who would complain about this sort of expenimentation would have few qualms about similar experimentation on living animals. This is further evidence that much of the world cares more about dead humans than about living animals.

8 This feature of our value system has also been referred to as speciesism and anthropocentrism; I prefer "narcissism."

${ }^{9}$ Calvin W. Schwabe, Unmentionable Cuisine (Charlottesville: University of Virginia Press, 1979), p. 167. 